\title{
Desmoplastic melanoma: Demographic and clinicopathological features and disease-specific prognostic factors
}

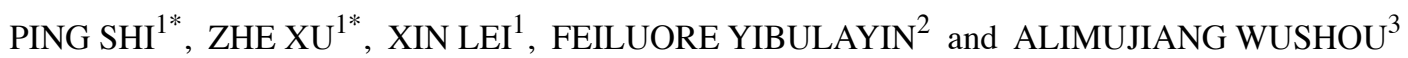 \\ ${ }^{1}$ Department of Stomatology, Shenzhen Longhua District Central Hospital, Shenzhen, Guangdong 518110; \\ ${ }^{2}$ Department of Preventive Medicine, School of Public Health; ${ }^{3}$ Department of Oral and Maxillofacial Surgery, \\ Shanghai Stomatological Hospital, Fudan University, Shanghai 200001, P.R. China
}

Received February 21, 2018; Accepted March 14, 2019

DOI: $10.3892 / \mathrm{ol} .2019 .10259$

\begin{abstract}
Desmoplastic melanoma (DM) is a rare morphological subtype of melanoma that remains uncharacterized. The aim of the present study was to investigate the incidence of DM, its general demographics, clinicopathological features and disease-specific prognostic factors. DM cases were sampled from the Surveillance, Epidemiology and End Results (SEER) program from between 1973 and 2017. A total of 3,657 cases (median age, 68 years) were identified. The results indicated that DM primarily occurred in Caucasian subjects, with a male-to-female ratio of 2:1. Statistically significant overall survival (OS) and disease-specific survival (DSS) rate differences were identified according to sex, age, treatment, $\mathrm{T}$ stage, $\mathrm{N}$ stage and SEER historic tumor stage $(\mathrm{P}<0.05)$. In multivariate Cox regression analysis, age $>68$ years, male sex, American Joint Committee on Cancer (AJCC) stage II and III, and SEER historic tumor stage of the regional tumor were all factors associated with poorer OS and DSS rates. The findings also revealed that surgical treatment was associated with favorable DSS and OS rates. In conclusion, DM occurred primarily in Caucasian subjects of 60-80 years of age, with predominance in males. Furthermore, age, sex, AJCC stage,
\end{abstract}

Correspondence to: Dr Alimujiang Wushou, Department of Oral and Maxillofacial Surgery, Shanghai Stomatological Hospital, Fudan University, 356 Beijing East Road, Shanghai 200001, P.R. China

E-mail:wushoua@fudan.edu.cn

*Contributed equally

Abbreviations: DM, desmoplastic melanoma; OS, overall survival; DSS, disease-specific survival; SEER, Surveillance, Epidemiology and End Results; AJCC, American Joint Committee on Cancer

Key words: desmoplastic melanoma, incidence, prognostic factor, Surveillance, Epidemiology and End Results
SEER historic tumor stage and surgical treatment were identified as independent prognostic factors of DM in terms of DSS and OS.

\section{Introduction}

Desmoplastic melanoma (DM) was first reported in 1971 as a rare morphological variant of melanoma composed of spindle melanocytes and abundant collagen (1). Subsequently, its histological definition was further expanded into two subtypes: 'Pure' DM, which is a uniform desmoplasia throughout the entire tumor, and 'mixed' DM, which is a desmoplasia in combination with other malignant cell types (2-4). The fibroblastic component of the tumoral stroma in DM is crucial to define its desmoplastic behavior (5).

DM differs from traditional melanomas in clinical presentation (6). The diagnosis of DM is challenging as DM predominantly presents as atypical and amelanotic lesions rather than a pigmented nevus (7). Compared with conventional melanomas, DM is locally aggressive, has a high incidence of local recurrence and a low incidence of regional metastasis (8). DM is more prevalent in older subjects and on sun-exposed areas of skin, particularly the head and neck region, and affects men more than women $(9,10)$. As with other melanomas, surgical treatment with wide local excision is the first-line therapy option and adjuvant radiation treatment may be used for advanced lesions $(6,11)$.

According to previously reported statistics based on Surveillance, Epidemiology, and End Results (SEER) studies in the USA, DM accounts for $\sim 4 \%$ of all melanoma cases and its incidence rate was $\sim 2 \times 10^{-6} \%$, which steadily increased between 1992 and $2013(12,13)$. However, understanding concerning DM behavior, clinical outcomes and prognostic factors is limited to several case reports and a small number of institutional reviews $(5,8,12-14)$. To the best of our knowledge, no large case studies have reported the general demographic and clinicopathological features or disease-specific prognostic factors of DM. Thus, a retrospective analysis of clinical cases using data from the SEER program was performed in the present study. 


\section{Materials and methods}

Data sources. Data from the present study is publicly available from the SEER program (seer.cancer.gov; National Cancer Institute; National Institute of Health, Bethesda, MD, USA), which collects incidence and survival data of patients with malignant tumors through 18 population-based cancer registries and represents $\sim 34 \%$ of the population of the USA $(12,13)$. Patients with a primary diagnosis of DM were identified using the third edition of the International Classification of Diseases for Oncology (ICD-O-3; code: $8745 / 3)(15)$. Cases were excluded if treatment or outcome data were unavailable for survival analysis. Overall data were obtained using SEER*Stat software (version 8.3.4; seer.cancer.gov/data/; National Cancer Institute; National Institute of Health).

Statistical analysis. Overall statistical analysis was performed using SPSS for Windows (version 23.0; IBM Corp., Armonk, IL, USA). A $\chi^{2}$ test was used to examine bivariate associations between categorical variables. Melanoma-specific and all-cause mortality rates were investigated. The primary endpoint was considered to be the date of DM-associated mortality. The time point between the date of diagnosis and the date of DM-associated mortality was defined as the disease-specific survival (DSS). Kaplan-Meier survival analyses with log-rank tests were used to estimate survival. Furthermore, Cox proportional hazards regression was used to estimate the hazard ratio. All statistical tests were two-tailed. $\mathrm{P}$-values were two-sided. $\mathrm{P}<0.05$ was considered to indicate a statistically significant difference.

\section{Results}

Demographic and clinicopathological characteristics. The primary aim of the present study was to determine the general demographics, incidence and tumor-specific clinicopathological features of DM. Table I summarizes the clinical and disease characteristics of the patients with DM patients. In brief, data collected between 1973 and 2107 on a total of 3,657 patients with DM were retrieved from SEER registries in the present study. The total cohort consisted of 2,476 males and 1,181 females, with a male-to-female ratio of $\sim 2: 1$. The median age was 68 years (range, 6-101 years). The age and sex distributions are presented in Fig. 1. Regarding the ethnicity distribution, $97 \%$ of the patients were Caucasian, and the remaining patients were of African descent or other. The data demonstrated that 3,635 cases of DM had originated from the skin, 13 cases from the nose and mouth, 3 cases from internal organs and 6 cases from other sites. Of the total number of cases, the pathological differentiation status in 3,611 patients was unknown (Table I), according to the American Joint Committee on Cancer (AJCC)/Union of International Cancer Control pathological grade system (16). Surgical treatment was the only recorded treatment modality. A total of 3,517 patients received surgical treatment.

Survival outcomes. Kaplan-Meier analysis was utilized for time-to-event analysis of overall survival (OS) and DSS rates. OS analysis was performed by stratifying different

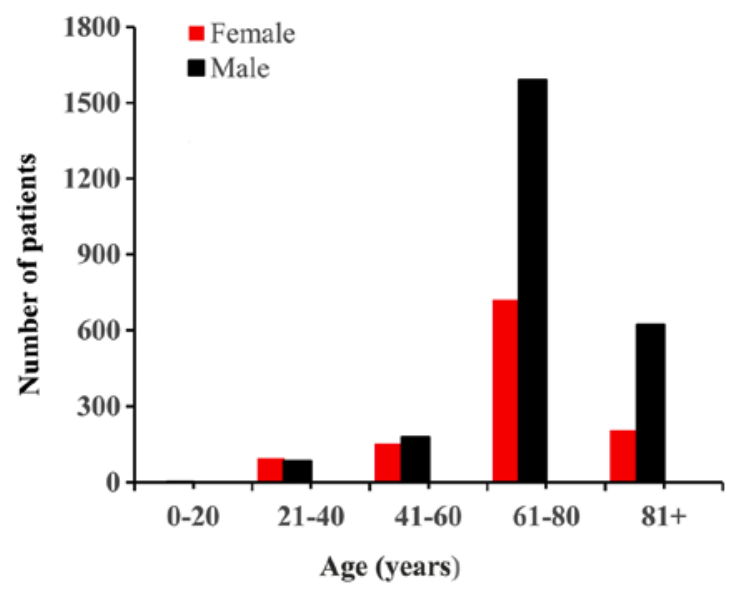

Figure 1. Age and sex distributions of patients with desmoplastic melanoma.

demographic and clinicopathological features of DM. Statistically significant differences were identified with regard to sex (female vs. male, $\mathrm{P}<0.001)$, age $(\leq 68$ vs. $>68$ years, $\mathrm{P}<0.001$ ), AJCC stage (I+II vs. III+IV, $\mathrm{P}<0.001$ ), SEER historic tumor stage (localized + regional vs. distant metastasis tumor, $\mathrm{P}<0.001)$, $\mathrm{T}$ stage $(\mathrm{TX}+\mathrm{T} 1+\mathrm{T} 2$ vs. $\mathrm{T} 3+\mathrm{T} 4, \mathrm{P}<0.001$; based on the Tumor-Node-Metastasis staging system (16): TX, T stage unknown; T0, no evidence of primary tumors; T1, tumor thickness $\leq 1.00 \mathrm{~mm}$; T2, tumor thickness $1.01 \mathrm{~mm}-2.0 \mathrm{~mm}$; T3, tumor thickness: $2.01 \mathrm{~mm}-4.0 \mathrm{~mm}$; T4, tumor thickness $\geq 4.0 \mathrm{~mm}$.), $\mathrm{N}$ stage (lymph node negative vs. lymph node positive, $\mathrm{P}<0.001$ ), $\mathrm{M}$ stage (M0 vs. $\mathrm{M} 1, \mathrm{P}<0.001$ ), treatment (surgery vs. non-surgery, $\mathrm{P}<0.001$ ), tumor location (skin vs. other site, $\mathrm{P}<0.001)$ and ethnicity (Caucasian vs. African descent vs. other, $\mathrm{P}<0.001$; Fig. 2). In the DSS analysis, significant differences were also identified regarding sex (female vs. male, $\mathrm{P}<0.001$ ), age ( $\leq 68$ vs. $>68$ years old, $\mathrm{P}<0.001$ ), SEER historic tumor stage (localized + regional vs. distant metastasis tumor, $\mathrm{P}<0.001$ ), treatment (surgery vs. non-surgery, $\mathrm{P}<0.001$ ), $\mathrm{T}$ stage $(\mathrm{TX}+\mathrm{T} 1+\mathrm{T} 2$ vs. $\mathrm{T} 3+\mathrm{T} 4, \mathrm{P}<0.001)$ and $\mathrm{N}$ stage (lymph node negative vs. lymph node positive, $\mathrm{P}<0.001$; Fig. 3 ).

Prognostic factors. A Cox proportional hazards regression model was constructed to evaluate predictors of OS and DSS (Table II). Univariate analysis of OS revealed the risk of mortality was significantly higher for patients that were aged $>68$ years old $(\mathrm{P}<0.001)$, male $(\mathrm{P}<0.001)$, had an AJCC stage of II, III or IV $(\mathrm{P}<0.001)$, an N stage of NX, N1 or N2 (NX stage, $\mathrm{P}<0.001$; $\mathrm{N} 1$ stage, $\mathrm{P}<0.001$; and $\mathrm{N} 2$ stage, $\mathrm{P}=0.002$ ) and an M stage of M1 $(\mathrm{P}<0.001)$. Univariate analysis of DSS indicated the risk of melanoma-induced mortality was significantly higher for patients that were aged $>68$ years old, male, had an AJCC stage of II, III or IV, an N stage of NX, N1 or N2 and an $\mathrm{M}$ stage of $\mathrm{M} 1(\mathrm{P}<0.001)$.

In the multivariate analysis, age $>68$ years old (OS and DSS, $\mathrm{P}<0.001)$, male sex (OS, $\mathrm{P}<0.001$; DSS, $\mathrm{P}=0.005)$, AJCC stage II and III (OS for stage II and III, P<0.001; DSS for stage II, $\mathrm{P}=0.009$; and DSS for stage III, $\mathrm{P}<0.001$ ) and SEER historic tumor stage (OS, $\mathrm{P}<0.001$; $\mathrm{DSS}, \mathrm{P}=0.009)$ were associated with poorer OS and DSS rates. Notably, surgical treatment was associated with favorable DDS and OS rates (OS, P<0.001S; DSS, P=0.015; Table III). 
Table I. Baseline characteristics of desmoplastic melanoma cases in the SEER database.

\begin{tabular}{|c|c|c|c|c|c|c|}
\hline \multirow[b]{2}{*}{ Characteristics } & \multicolumn{3}{|c|}{ Overall survival } & \multicolumn{3}{|c|}{ Melanoma-specific survival } \\
\hline & Alive & Dead & P-value & Alive & Dead & P-value \\
\hline Age, years & & & $<0.001$ & & & - \\
\hline$\leq 68$ & 1,278 & 320 & & 689 & 137 & \\
\hline$>68$ & 947 & 1,112 & & 0 & 0 & \\
\hline Sex & & & $<0.001$ & & & $<0.001$ \\
\hline Female & 807 & 374 & & 321 & 41 & \\
\hline Male & 1,418 & 1,058 & & 368 & 96 & \\
\hline Ethnicity & & & 0.026 & & & 0.995 \\
\hline Caucasian & 2,149 & 1,403 & & 655 & 130 & \\
\hline African descent & 15 & 9 & & 10 & 2 & \\
\hline Other & 61 & 20 & & 24 & 5 & \\
\hline Tumor site & & & 0.014 & & & 0.548 \\
\hline Internal organs & 1 & 2 & & 1 & 0 & \\
\hline Nose and mouth & 7 & 6 & & 5 & 0 & \\
\hline Skin & 2,217 & 1,418 & & 683 & 137 & \\
\hline Other & 0 & 6 & & 0 & 0 & \\
\hline Grade & & & 0.216 & & & 0.451 \\
\hline I & 1 & 2 & & 0 & 0 & \\
\hline II & 6 & 3 & & 2 & 0 & \\
\hline III & 10 & 15 & & 2 & 1 & \\
\hline IV & 5 & 4 & & 1 & 1 & \\
\hline Unknown & 2,203 & 1,408 & & 686 & 135 & \\
\hline AJCC stage & & & $<0.001$ & & & $<0.001$ \\
\hline I & 663 & 178 & & 187 & 15 & \\
\hline II & 792 & 383 & & 184 & 26 & \\
\hline III & 68 & 44 & & 23 & 11 & \\
\hline IV & 25 & 50 & & 12 & 3 & \\
\hline T stage & & & $<0.001$ & & & 0.073 \\
\hline T0 & 6 & 8 & & 2 & 0 & \\
\hline $\mathrm{T} 1$ & 365 & 109 & & 107 & 11 & \\
\hline $\mathrm{T} 2$ & 376 & 106 & & 104 & 8 & \\
\hline $\mathrm{T} 3$ & 387 & 171 & & 94 & 10 & \\
\hline $\mathrm{T} 4$ & 455 & 275 & & 109 & 25 & \\
\hline $\mathrm{TX}$ & 116 & 64 & & 33 & 4 & \\
\hline $\mathrm{N}$ stage & & & $<0.001$ & & & 0.012 \\
\hline No & 1,572 & 628 & & 405 & 44 & \\
\hline $\mathrm{N} 1$ & 47 & 38 & & 19 & 7 & \\
\hline $\mathrm{N} 2$ & 22 & 15 & & 6 & 2 & \\
\hline $\mathrm{NX}$ & 64 & 52 & & 19 & 5 & \\
\hline M stage & & & $<0.001$ & & & $<0.001$ \\
\hline M0 & 1,654 & 660 & & 465 & 59 & \\
\hline M1 & 23 & 51 & & 169 & 53 & \\
\hline MX & 28 & 22 & & 1 & 0 & \\
\hline SEER stage & & & $<0.001$ & & & $<0.001$ \\
\hline Localized & 1,486 & 710 & & 465 & 59 & \\
\hline Regional & 603 & 562 & & 169 & 53 & \\
\hline Distant & 4 & 7 & & 1 & 0 & \\
\hline Unstaged & 77 & 50 & & 33 & 9 & \\
\hline
\end{tabular}


Table I. Continued.

\begin{tabular}{|c|c|c|c|c|c|c|}
\hline \multirow[b]{2}{*}{ Characteristics } & \multicolumn{3}{|c|}{ Overall survival } & \multicolumn{3}{|c|}{ Melanoma-specific survival } \\
\hline & Alive & Dead & P-value & Alive & Dead & P-value \\
\hline Treatment & & & 0.017 & & & 0.075 \\
\hline Non-surgery & 67 & 69 & & 19 & 3 & \\
\hline Surgery & 2,156 & 1,361 & & 670 & 133 & \\
\hline
\end{tabular}

SEER, Surveillance, Epidemiology and End Results; AJCC, American joint committee on cancer; T, tumor; N, node; M, metastasis; TX, T stage unknown; NX, N stage unknown; MX, M stage unknown.
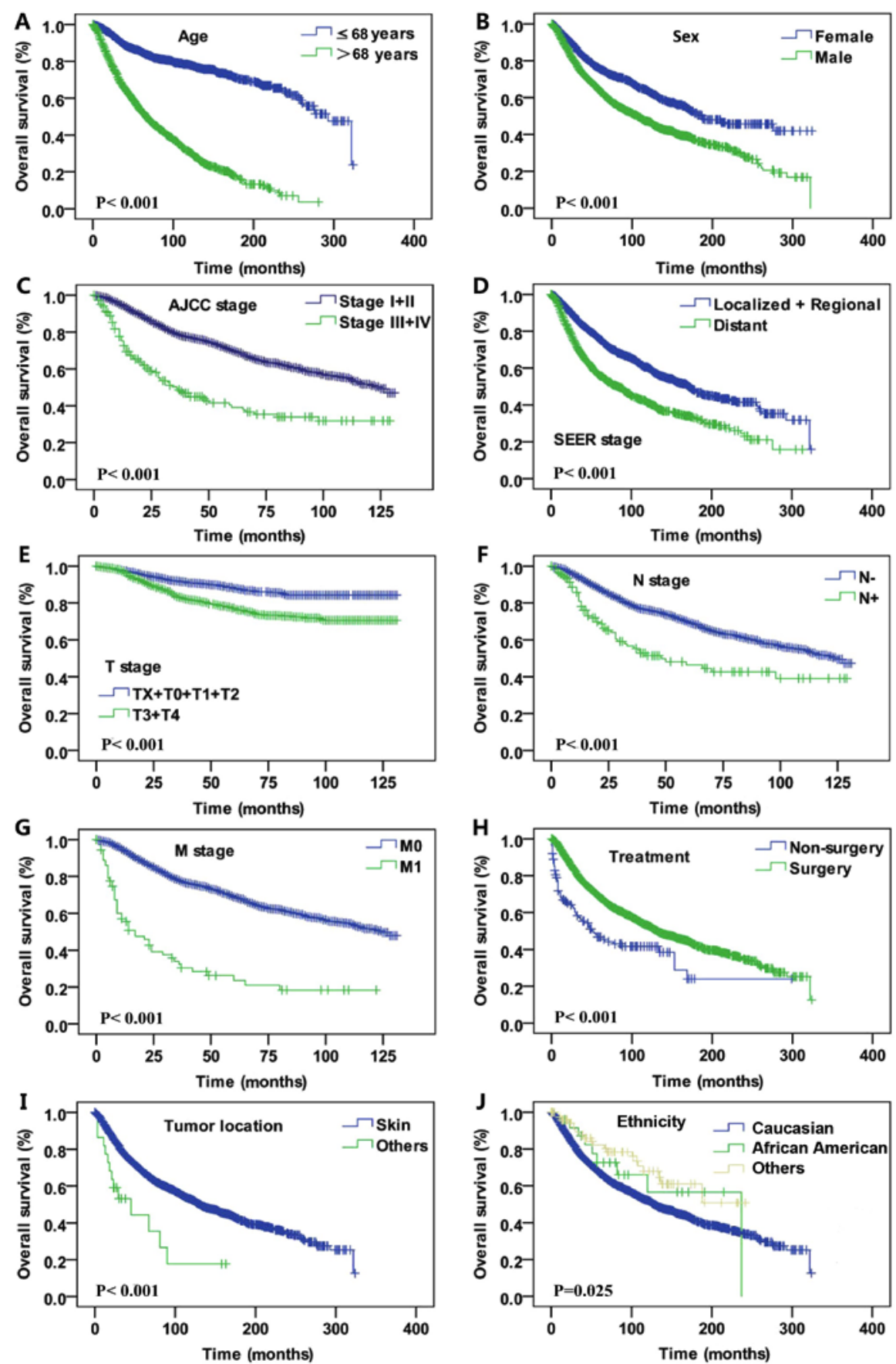

Figure 2. Kaplan-Meier curves for overall survival rate. Kaplan-Meier curves for overall survival according to (A) age, (B) sex, (C) AJCC stage, (D) SEER historic tumor stage, (E) T stage, (F) N stage, (G) M stage, (H) treatment, (I) tumor location and (J) ethnicity. T, tumor; N, node; M, metastasis; SEER, Surveillance, Epidemiology and End Results AJCC, American Joint Committee on Cancer. 

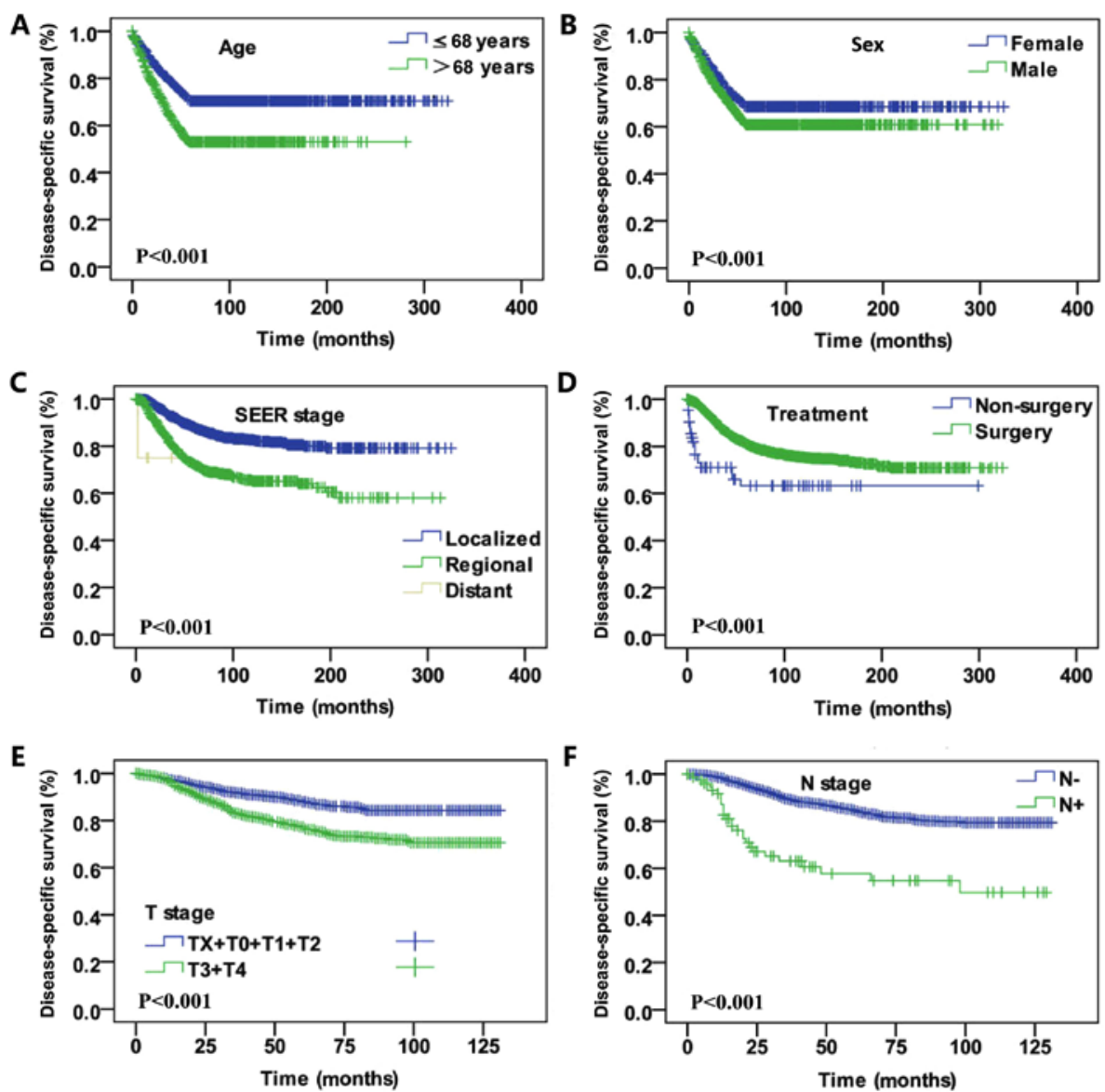

Figure 3. Kaplan-Meier curves for disease-specific survival rate. Kaplan-Meier curves for disease-specific survival according to (A) age, (B) sex, (C) SEER historic tumor stage, (D) treatment, (E) T stage and (F) N stage. T, tumor; N, node; SEER, Surveillance, Epidemiology and End Results.

\section{Discussion}

DM is a rare variant of melanoma that can be easily misdiagnosed. Clinically, the appearance of DM is often nonspecific and amelanotic $(5,17)$. Histologically, DM can mimic a range of benign and malignant neoplasms with spindle cells and fibrous stroma (7). Dermoscopy and reflectance confocal microscopy are useful tools for the identification of DM, though immunohistochemical panels are needed for the final diagnosis $(18,19)$. The diagnostic criteria of DM have become more consistent, and the misdiagnosis of DM has decreased in patients $(2,20)$. However, due to the rarity of DM, its clinical and prognostic characteristics have yet to be completely elucidated.

The present study indicated that the presentation of DM was associated with increased age. Notably, the incidence of DM was highest in the 6-8th decade of life, with predominance in males. Furthermore, the present findings revealed that DM primarily originated from the skin. Of note, people of Caucasian ethnicity accounted for the majority of the study population. This is in accordance with previous studies $(5,8,12-14,21)$. In previous studies, the male-to-female ratio was 2.3-3.7, and the trend of incidence in males was suggested to be greater $(12,13)$. The current large population study of DM also revealed a predominance of DM in males.

One of the main aims of the present study was to identify prognostic factors in patients with DM. The results demonstrated that sex and age were independent prognostic factors for DSS and OS. These results are in accordance with previous studies $(12,13)$. However, other studies reported that the sex and age of patients with DM were associated with poorer OS, but not poorer DSS $(14,22)$. The inconsistency in results may be due to the substantial limitation of the study population. As DM primarily occurred in older people, comorbidities should also be taken into consideration, which could not be obtained from the SEER Program in the present study.

Since DM has a low rate of nodal metastasis, investigators have suggested that routine sentinel node biopsy may be not necessary $(6,23-25)$. Conversely, certain studies have indicated that DM sentinel lymph node biopsies may have a higher positive rate than previous thought, thus sentinel node biopsy should be considered $(26,27)$. In addition, previous studies revealed that DM did not share the same traditional prognostic factors with traditional malignant melanoma, and nodal positivity did not predict survival (6). However, other researchers have proposed that the potential for regional nodal involvement in patients with DM must be considered from its diagnosis to surveillance for recurrence, particularly in 'mixed' DM $(9,28,29)$. An explanation for these contradictory views may be that the subtypes of DM, including 'pure' or 'mixed' DM, could impact on the clinical behaviors and prognosis differently $(22,30)$. In the present study, the percentage of lymph node metastasis was $\sim 5 \%$, and in the multivariate Cox regression analysis the $\mathrm{N}$ stage was not an independent prognostic indicator. Therefore, the present 
Table II. Univariate Cox regression analysis of clinicopathological parameters in desmoplastic melanoma for DSS and OS.

\begin{tabular}{|c|c|c|c|c|}
\hline \multirow[b]{2}{*}{ Parameters } & \multicolumn{2}{|l|}{ OS } & \multicolumn{2}{|l|}{ DSS } \\
\hline & HR (95\% CI) & P-value & HR (95\% CI) & P-value \\
\hline \multicolumn{5}{|l|}{ Age, years } \\
\hline$\leq 68$ & 1.0 (Reference) & & 1.0 (Reference) & \\
\hline$>68$ & $4.595(4.043-5.223)$ & $<0.001$ & $3.083(2.517-3.777)$ & $<0.001$ \\
\hline \multicolumn{5}{|l|}{ Ethnicity } \\
\hline Caucasian & 1.0 (Reference) & & 1.0 (Reference) & \\
\hline African descent & $0.747(0.388-1.438)$ & 0.382 & $0.880(0.329-4.129)$ & 0.800 \\
\hline Other & $0.566(0.364-0.880)$ & 0.011 & $0.452(0.187-1.093)$ & 0.078 \\
\hline \multicolumn{5}{|l|}{ Sex } \\
\hline Female & 1.0 (Reference) & & 1.0 (Reference) & \\
\hline Male & $1.639(1.456-1.844)$ & $<0.001$ & $1.808(1.448-2.258)$ & $<0.001$ \\
\hline \multicolumn{5}{|l|}{ Tumor location } \\
\hline Internal organs & 1.0 (Reference) & & 1.0 (Reference) & \\
\hline Nose and mouth & $0.793(0.160-3.934)$ & 0.777 & $0.615(0.056-6.788)$ & 0.691 \\
\hline Skin & $0.464(0.116-1.858)$ & 0.278 & $0.311(0.044-2.218)$ & 0.244 \\
\hline Other site & $2.839(0.573-14.079)$ & 0.201 & $35.024(3.047-402.601)$ & 0.004 \\
\hline \multicolumn{5}{|l|}{ Grade } \\
\hline I & 1.0 (Reference) & & 1.0 (Reference) & \\
\hline II & $0.650(0.109-3.892)$ & 0.637 & $0.485(0.030-7.761)$ & 0.609 \\
\hline III & $2.563(0.568-11.212)$ & 0.211 & $1.791(0.209-15.343)$ & 0.595 \\
\hline IV & $1.060(0.194-5.788)$ & 0.946 & $1.045(0.095-11.252)$ & 0.971 \\
\hline Unknown & $0.719(0.180-2.879)$ & 0.641 & $0.468(0.066-3.333)$ & 0.449 \\
\hline \multicolumn{5}{|l|}{ AJCC stage } \\
\hline I & 1.0 (Reference) & & 1.0 (Reference) & \\
\hline II & $1.693(1.417-2.022)$ & $<0.001$ & $2.031(1.422-2.901)$ & $<0.001$ \\
\hline III & $2.570(1.847-3.577)$ & $<0.001$ & $5.693(3.444-9.412)$ & $<0.001$ \\
\hline IV & $6.210(4.533-8.509)$ & $<0.001$ & $11.207(6.571-19.113)$ & $<0.001$ \\
\hline \multicolumn{5}{|l|}{ T stage } \\
\hline T0 & 1.0 (Reference) & & 1.0 (Reference) & \\
\hline $\mathrm{T} 1$ & $0.281(0.137-0.577)$ & 0.001 & $1.800(0.414-7.831)$ & 0.433 \\
\hline $\mathrm{T} 2$ & $0.252(0.123-0.517)$ & $<0.001$ & $0.452(0.239-0.855)$ & 0.015 \\
\hline $\mathrm{T} 3$ & $0.384(0.189-0.781)$ & 0.008 & $0.484(0.2630 .891)$ & 0.020 \\
\hline $\mathrm{T} 4$ & $0.521(0.258-1.052)$ & 0.069 & $0.779(0.441-1.379)$ & 0.392 \\
\hline $\mathrm{TX}$ & $0.428(0.205-0.891)$ & 0.024 & $1.329(0.783-2.254)$ & 0.292 \\
\hline \multicolumn{5}{|l|}{$\mathrm{N}$ stage } \\
\hline No & 1.0 (Reference) & & 1.0 (Reference) & \\
\hline N1 & $1.958(1.41-2.717)$ & $<0.001$ & $3.297(2.050-5.301)$ & $<0.001$ \\
\hline $\mathrm{N} 2$ & $2.255(1.351-3.764)$ & $<0.001$ & $5.364(2.632-10.929)$ & $<0.001$ \\
\hline $\mathrm{NX}$ & $1.791(1.350-2.377)$ & $<0.001$ & $2.591(1.612-4.615)$ & $<0.001$ \\
\hline \multicolumn{5}{|l|}{ M stage } \\
\hline M0 & 1.0 (Reference) & $<0.001$ & 1.0 (Reference) & \\
\hline M1 & $4.533(3.407-6.033)$ & $<0.001$ & $7.114(4.527-11.181)$ & $<0.001$ \\
\hline MX & $1.185(0.774-1.813)$ & 0.434 & $0.773(0.287-2.084)$ & 0.611 \\
\hline \multicolumn{5}{|l|}{ SEER stage } \\
\hline Localized & 1.0 (Reference) & & 1.0 (Reference) & \\
\hline Regional & $1.816(1.625-2.029)$ & $<0.001$ & $2.345(1.890-2.9120)$ & $<0.001$ \\
\hline Distant & $10.773(5.098-22.767)$ & $<0.001$ & $8.951(1.249-64.162)$ & 0.029 \\
\hline Unstaged & $1.212(0.910-1.615)$ & 0.189 & $1.127(0.595-2.134)$ & 0.714 \\
\hline
\end{tabular}


Table II. Continued.

\begin{tabular}{lccc}
\hline & \multicolumn{2}{c}{ OS } & DSS \\
\cline { 2 - 3 } Parameters & HR $(95 \% \mathrm{CI})$ & P-value & HR $(95 \%$ CI) \\
\hline $\begin{array}{l}\text { Treatment } \\
\text { Non-surgery } \\
\text { Surgery }\end{array}$ & 1.0 (Reference) & & \\
\hline
\end{tabular}

SEER, Surveillance, Epidemiology and End Results; AJCC, American joint committee on cancer; T, tumor; N, node; M, metastasis; TX, T stage unknown; NX, N stage unknown; MX, M stage unknown.

Table III. Multivariate Cox regression analysis of clinicopathological parameters in desmoplastic melanoma for DSS and OS.

\begin{tabular}{|c|c|c|c|c|}
\hline \multirow[b]{2}{*}{ Parameters } & \multicolumn{2}{|c|}{ OS } & \multicolumn{2}{|c|}{ DSS } \\
\hline & $\mathrm{HR}(95 \% \mathrm{CI})$ & P-value & HR $(95 \%$ CI) & P-value \\
\hline \multicolumn{5}{|l|}{ Age, years } \\
\hline$\leq 68$ & 1.0 (Reference) & & 1.0 (Reference) & \\
\hline$>68$ & $4.225(3.454-5.242)$ & $<0.001$ & $3.055(2.204-4.235)$ & $<0.001$ \\
\hline \multicolumn{5}{|l|}{ Sex } \\
\hline Female & 1.0 (Reference) & & 1.0 (Reference) & \\
\hline Male & $1.465(1.207-1.777)$ & $<0.001$ & $1.673(1.169-2.392)$ & 0.005 \\
\hline \multicolumn{5}{|l|}{ AJCC stage } \\
\hline I & 1.0 (Reference) & & 1.0 (Reference) & $<0.001$ \\
\hline II & $1.434(1.174-1.750)$ & $<0.001$ & $1.716(1.145-2.572)$ & 0.009 \\
\hline III & $2.305(1.578-3.367)$ & $<0.001$ & $4.180(2.252-7.756)$ & $<0.001$ \\
\hline IV & $0.001(0.000-1.037)$ & 0.948 & $0.000(0.000-5.328)$ & 0.965 \\
\hline \multicolumn{5}{|c|}{ SEER historic stage } \\
\hline Localized & 1.0 (Reference) & & 1.0 (Reference) & \\
\hline Regional & $1.467(1.215-1.770)$ & $<0.001$ & $1.615(1.127-2.315)$ & 0.009 \\
\hline Distant & $1.937(0.528-3.392)$ & 0.932 & $1.827(0.392-5.874)$ & 0.952 \\
\hline \multicolumn{5}{|l|}{ Treatment } \\
\hline Non-surgery & 1.0 (Reference) & & 1.0 (Reference) & \\
\hline Surgery & $0.317(0.199-0.504)$ & $<0.001$ & $0.234(0.073-0.751)$ & 0.015 \\
\hline
\end{tabular}

OS, overall survival; DSS, disease-specific survival; SEER, Surveillance, Epidemiology and End Results; AJCC, American Joint Committee on Cancer; HR, hazard ratio; CI, confidence interval.

results indicate that sentinel node biopsy may be not useful for DM.

Previous studies have demonstrated that DM had a propensity for local recurrence and distant metastasis, particularly with regard to the 'pure' DM subtype $(8,23,25)$. Furthermore, local recurrence was observed to be associated with an increased risk of systemic metastatic disease (31). In the current study, the proportion of $\mathrm{M} 1+\mathrm{MX}$ stage tumor was $\leq 5 \%$, and M1 stage was associated with poorer OS and DSS rates, according to univariate analysis. Furthermore, advanced AJCC and SEER stages were associated with poorer OS and DSS rates. This is in accordance with previous studies $(9,13)$.
These data support the idea that detection of DM at its early stage is difficult and missed diagnosis can impact the overall prognosis $(7,32)$. Delayed diagnosis of DM is likely due to its relative rarity and atypical clinical presentation $(8,17)$.

Previous studies have suggested that surgical margins are critical in the management of DM local recurrence and that wide surgical resection margins are required $(6,9,33)$. In the present study, a total of 3,517 patients received surgical treatment; however, data on the surgical margins were absent in the SEER database. The results indicated that surgical treatment was associated with favorable DDS and OS. This is in accordance with previous results (13). 
In conclusion, use of the National Cancer Institute SEER registries in the present study extended the current knowledge of DM. The large number of patients enabled description of the demographic and clinicopathological features and disease-specific prognostic factors of DM. Compared with other studies, a notable strength of the present study was its robust long-term follow-up assessment of survival provided by the SEER database. However, there were several limitations of the current study. Notably, the study could not differentiate between the DM subtypes. This was because the SEER registry is coded according to the final diagnosis obtained from a pathology report and only applied the ICD-O-3 morphology code for all types of DM. In addition, not all cases had complete information, and these missing data undoubtedly weaken the strength of the current investigation. As aforementioned, certain important prognostic data, including pathological grade, surgical types, margin status and adjuvant therapies, were either absent or incomplete in the SEER database. Therefore, the influences of these factors on the overall prognosis could not be assessed. In addition, the patients with DM represented an older population and there was a lack of comorbidity data, which may significantly affect treatment protocol and outcomes.

In conclusion, to the best of our knowledge, the present study is the first to report on a large case series concerning the demographics, clinicopathological features and disease-specific prognostic factors of DM. The results demonstrated that DM primarily occurred in Caucasians, with a predominance in males, and the highest incidence occurred in the 6-8th decades of life. Age, sex, AJCC stage, SEER historic stage and surgical treatment were identified as independent prognostic factors for DSS and OS rates.

\section{Acknowledgements}

Not applicable.

\section{Funding}

The present study was supported by The Scientific Research Foundation of Shanghai Stomatological Hospital, Fudan University (Shanghai, China; grant no. SSDCZ-2016-01).

\section{Availability of data and materials}

The datasets generated during the present study are available in the official software SEER*Stat v.8.3.4 repository (https://seer. cancer.gov/data/).

\section{Authors' contributions}

ZX and PS were major contributors in writing the manuscript. PS designed the experiments, wrote the original draft and revised the manuscript. ZX was responsible for analysis of the data and revising the manuscript. XL and FY collected and interpreted patient data. AW was responsible for planning, organizing, checking the data and the manuscript throughout the project. All authors read and approved the final manuscript.

\section{Ethics approval and consent to participate}

Due to the retrospective nature of this study, it was granted an exemption in writing by the University of Fudan Institutional Review Board (Shanghai, China).

\section{Patient consent for publication}

Not applicable.

\section{Competing interests}

The authors declare that they have no competing interests.

\section{References}

1. Conley J, Lattes R and Orr W: Desmoplastic malignant melanoma (a rare variant of spindle cell melanoma). Cancer 28: 914-936, 1971.

2. Weissinger SE, Keil P, Silvers DN, Klaus BM, Möller P, Horst BA and Lennerz JK: A diagnostic algorithm to distinguish desmoplastic from spindle cell melanoma. Mod Pathol 27: 524-534, 2014.

3. Magro CM, Crowson AN and Mihm MC: Unusual variants of malignant melanoma. Mod Pathol 19 (Suppl 2): S41-S70, 2006.

4. Reed RJ and Leonard DD: Neurotropic melanoma. A variant of desmoplastic melanoma. Am J Surg Pathol 3: 301-311, 1979.

5. Manfredini M, Pellacani G, Losi L, Maccaferri M, Tomasi A and Ponti G: Desmoplastic melanoma: A challenge for the oncologist. Future Oncol 13: 337-345, 2017.

6. Wasif N, Gray RJ and Pockaj BA: Desmoplastic melanoma-the step-child in the melanoma family? J Surg Oncol 103: 158-162, 2011.

7. Mărgăritescu I and Chiriţă AD: Desmoplastic melanoma-challenges in the diagnosis and management of a rare cutaneous tumor. Rom J Morphol Embryol 55: 947-952, 2014.

8. Pace CS, Kapil JP, Wolfe LG, Kaplan BJ and Neifeld JP: Desmoplastic melanoma: Clinical behavior and management implications. Eplasty 16: e3, 2016.

9. Posther KE, Selim MA, Mosca PJ, Stanley WE, Johnson JL, Tyler DS and Seigler HF: Histopathologic characteristics, recurrence patterns, and survival of 129 patients with desmoplastic melanoma. Ann Surg Oncol 13: 728-739, 2006.

10. Lens MB, Newton-Bishop JA and Boon AP: Desmoplastic malignant melanoma: A systematic review. Br J Dermatol 152: 673-678, 2005.

11. Oliver DE, Patel KR, Switchenko J, Parker D, Lawson DH, Delman KA, Kudchadkar RR and Khan MK: Roles of adjuvant and salvage radiotherapy for desmoplastic melanoma. Melanoma Res 26: 35-41, 2016.

12. Khan F, Strohl A, Allen PD and Doerr TD: Desmoplastic melanoma of the head and neck: Incidence and survival, 1992-2013. Otolaryngol Head Neck Surg 157: 648-656, 2017.

13. Feng Z, Wu X, Chen V, Velie E and Zhang Z: Incidence and survival of desmoplastic melanoma in the United States, 1992-2007. J Cutan Pathol 38: 616-624, 2011.

14. Han D, Han G, Zhao X, Rao NG, Messina JL, Marzban SS, Sarnaik AA, Cruse CW, Sondak VK and Zager JS: Clinicopathologic predictors of survival in patients with desmoplastic melanoma. PLoS One 10: e0119716, 2015.

15. Fritz A, Percy C, Jack A, Shanmugarathan S, Sobin L, Parkin DM and Whelan S: International classification of diseases for oncology (ICD-O-3). World Health Organization, 2000.

16. Edge SB and Compton CC: The American Joint Committee on Cancer: The 7th edition of the AJCC cancer staging manual and the future of TNM. Ann Surg Oncol 17: 1471-1474, 2010

17. Machado I, Llombart B, Cruz J, Traves V, Requena C, Nagore E, Parafioriti A, Monteagudo C and Llombart-Bosch A: Desmoplastic melanoma may mimic a cutaneous peripheral nerve sheath tumor: Report of 3 challenging cases. J Cutan Pathol 44: 632-638, 2017.

18. Plaza JA, Bonneau P, Prieto V, Sangueza M, Mackinnon A, Suster D, Bacchi C, Estrozi B, Kazakov D, Kacerovska D, et al: Desmoplastic melanoma: An updated immunohistochemical analysis of 40 cases with a proposal for an additional panel of stains for diagnosis. J Cutan Pathol 43: 313-323, 2016. 
19. Maher NG, Solinas A, Scolyer RA, Puig S, Pellacani G and Guitera P: Detection of desmoplastic melanoma with dermoscopy and reflectance confocal microscopy. J Eur Acad Dermatol Venereol 31: 2016-2024, 2017.

20. LawrenceNF,HammondMR,FrederickDT,Su Y,Dias-SantagataD, Deng A, Selim MA, Mahalingam M, Flaherty KT and Hoang MP: Ki-67, p53, and p16 expression, and G691S RET polymorphism in desmoplastic melanoma (DM): A clinicopathologic analysis of predictors of outcome. J Am Acad Dermatol 75: 595-602, 2016.

21. Lorcy S, Koeppel MC, Richard MA, Grob JJ, Berbis P and Morand JJ: Desmoplastic melanoma: a study of 23 cases at 3 centres in the Bouches-du-Rhone region. Ann Dermato Venereol 141: 656-662, 2014.

22. Murali R, Zannino D, Synnott M, McCarthy SW, Thompson JF and Scolyer RA: Clinical and pathological features of metastases of primary cutaneous desmoplastic melanoma. Histopathology 58: 886-895, 2011.

23. Sims JR, Wieland CN, Kasperbauer JL, Moore EJ and Price DL: Head and neck desmoplastic melanoma: Utility of sentinel node biopsy. Am J Otolaryngol 38: 537-541, 2017.

24. Mohebati A, Ganly I, Busam KJ, Coit D, Kraus DH, Shah JP and Patel SG: The role of sentinel lymph node biopsy in the management of head and neck desmoplastic melanoma. Ann Surg Oncol 19: 4307-4313, 2012.

25. Murali R, Shaw HM, Lai K, McCarthy SW, Quinn MJ, Stretch JR, Thompson JF and Scolyer RA: Prognostic factors in cutaneous desmoplastic melanoma: A study of 252 patients. Cancer 116 : 4130-4138, 2010

26. Egger ME, Huber KM, Dunki-Jacobs EM, Quillo AR Scoggins CR, Martin RC II, Stromberg AJ, McMasters KM and Callender GG: Incidence of sentinel lymph node involvement in a modern, large series of desmoplastic melanoma. J Am Coll Surg 217: 37-45, 2013.

27. Broer PN, Walker ME, Goldberg C, Buonocore S, Braddock DT, Lazova R, Narayan D and Ariyan S: Desmoplastic melanoma: A 12-year experience with sentinel lymph node biopsy. Eur J Surg Oncol 39: 681-685, 2013
28. Dunne JA, Wormald JC, Steele J, Woods E, Odili J and Powell BW: Is sentinel lymph node biopsy warranted for desmoplastic melanoma? A systematic review. J Plast Reconstr Aesthet Surg 70: 274-280, 2017.

29. Pawlik TM, Ross MI, Prieto VG, Ballo MT, Johnson MM, Mansfield PF, Lee JE, Cormier JN and Gershenwald JE: Assessment of the role of sentinel lymph node biopsy for primary cutaneous desmoplastic melanoma. Cancer 106: 900-906, 2006.

30. Busam KJ, Mujumdar U, Hummer AJ, Nobrega J, Hawkins WG, Coit DG and Brady MS: Cutaneous desmoplastic melanoma: Reappraisal of morphologic heterogeneity and prognostic factors. Am J Surg Pathol 28: 1518-1525, 2004.

31. Jaroszewski DE, Pockaj BA, DiCaudo DJ and Bite U: The clinical behavior of desmoplastic melanoma. Am J Surg 182: 590-595, 2001.

32. Trayanova E, Chokoeva AA, Patterson JW, Wollina U, Lotti T and Tchernev G: Desmoplastic malignant melanoma associated with pigmented ocular tumor: Second documented problematic case from the board of adcrstr-association for dermatohistopathologic control, re-evaluation and subsequent therapeutic recommendations. J Biol Regul Homeost Agents 29 (1 Suppl): S59-S64, 2015.

33. Maurichi A, Miceli R, Camerini T, Contiero P, Patuzzo R, Tragni G, Crippa F, Romanidis K, Ruggeri R, Carbone A and Santinami M: Pure desmoplastic melanoma: A melanoma with distinctive clinical behavior. Ann Surg 252: 1052-1057, 2010.

(i) (3) This work is licensed under a Creative Commons cc) $\mathrm{EY}$ NG ND Attribution-NonCommercial-NoDerivatives 4.0 International (CC BY-NC-ND 4.0) License. 